\title{
Quality of Ground Water in the Biscayne Aquifer in Miami-Dade, Broward, and Palm Beach Counties, Florida, 1996-1998, with Emphasis on Contaminants
}

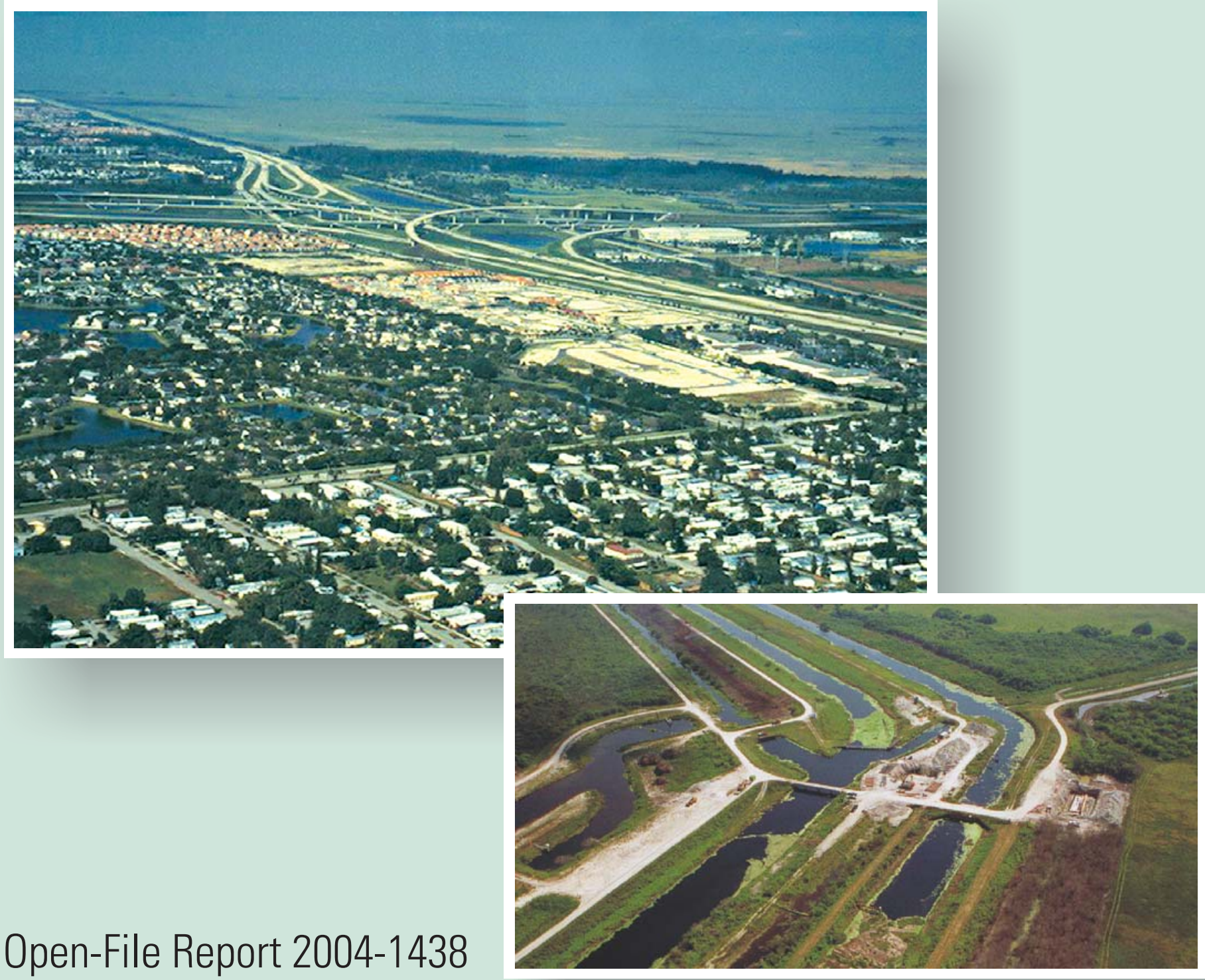

